\title{
EDUCAÇÃO E DIVERSIDADE: DEMANDAS DO CAPITALISMO CONTEMPORÂNEO
}

\author{
MARY ÂNGELA F. GERALDES* \\ ROSEMARY ROGGERO**
}

\begin{abstract}
RESUMO: $\mathrm{O}$ artigo apresenta o conceito de diversidade cultural, considerando o movimento do capitalismo contemporâneo e identificando as demandas da Organização das Nações Unidas para a Educação, a Ciência e a Cultura (UNESCO), assim como a forma como o Estado brasileiro vem respondendo a essas demandas, no sentido de uma educação para a diversidade. Chama a atenção para o modo como a indústria cultural é fomentada nesse contexto, no âmbito da educação para a sociedade de consumo. Conclui com uma abordagem sobre as tensões decorrentes do uso do conceito de diversidade, que desafiam a educação a encontrar estratégias para sua superação, embora o diálogo intercultural ainda encontre muitos obstáculos.
\end{abstract}

Palavras-chave: Educação. Diversidade. Sociedade do consumo. Políticas públicas. Indústria cultural.

\section{EDUCATION AND DIVERSITY: DEMANDS OF CONTEMPORARY CAPITALISM}

ABSTRACT: This paper presents the concept of cultural diversity. It considers the movement of contemporary capitalism and identifies both unEsco's demands and how the Brazilian state has responded to them to move towards an education for diversity. It draws attention to how the culture industry is nurtured, in that context, on consumer education. Its conclusion tackles the tensions arising from the use of the concept of diversity, which challenge education to find strategies to ovecome them, since the intercultural dialog is still faced with several obstacles.

Key words: Education. Diversity. Consumer society. Public policies. Culture industry.

\footnotetext{
* $\quad$ Mestre em Semiótica, Tecnologias de Informação e Educação pela Universidade Braz Cubas. E-mail: marygeraldes@hotmail.com

** Doutora em Educação: História, Política, Sociedade e docente do Programa de Pós-Graduação em Educação na Universidade Nove de Julho. E-mail: roseroggero@uol.com.br
} 


\section{ÉDUCATION ET DIVERSITÉ: DEMANDES DU CAPITALISME CONTEMPORAIN}

RÉSUMÉ: Cet article présente le concept de diversité culturelle en prenant en compte le mouvement du capitalisme contemporain et en identifiant les demandes de l' UNESCO, ainsi que la manière dont l'état brésilien répond à ces demandes pour s'orienter vers une éducation à la diversité. Il attire l'attention sur la manière dont l'industrie culturelle est stimulée, dans ce contexte, par l'éducation pour la société de consommation. Sa conclusion examine les tensions découlant de l'usage du concept de diversité qui défient l'éducation à trouver des stratégies pour les dépasser, car le dialogue interculturel se heurte encore à de nombreux obstacles.

Mots-clés: Éducation. Diversité. Société de la consommation. Politiques publiques. Industrie culturelle.

1 vida contemporânea emerge repleta de exigências de ampliações do universo de conhecimentos de que cada um dispõe na relação com o trabalho e com outras áreas do relacionamento humano. Como vivemos numa sociedade de consumo, o conhecimento tornou-se mercadoria e sujeito a normas paradoxais em relação à sua natureza. Como diz o arqueólogo espanhol Emiliano Aguirre (2006-2007, p. 1): “O conhecimento enriquece e se distingue do dinheiro porque busca comunicar-se, não concentrar-se". Assim, a economia capitalista força a natureza das coisas a se encaixar à sua lógica, sempre de forma artificial e arbitrária.

$\mathrm{Na}$ infindável carta de produtos e serviços a que somos submetidos cotidianamente, entretanto, há uma repetição fastidiosa que acaba por tornar desestimulante e tedioso o consumo, ainda que esteja sempre presente um descompasso entre essa sensação e algo semelhante a uma necessidade de conferir se não há nada de novo a ser consumido. Esse novo deve aparentar ser, ao mesmo tempo, algo diferenciado.

Numa palestra sobre turismo, Luiz Trigo afirmava que as pessoas que viajam estão em busca de experiências diferenciadas do seu cotidiano, algo que as tire do sempre igual e as remeta ao sonho, à ideia de que haja outra realidade possível. Ainda assim, vemos que o mundo parece um lugar ora com possibilidades finitas de oferta de mercadorias que gerem em especial a satisfação de desejos cada vez mais abstratos, estimulados pelo próprio jogo mercadológico, ora um lugar de possibilidades infinitas que se desenrolam num campo em que a diversidade pode ser vista como um princípio: o da cultura.

Não é de se estranhar, então, que a questão da diversidade cultural comece a ganhar centralidade nos debates, em âmbito global, e com ela uma série de recomendações a respeito da conveniência de uma educação para a diversidade. 
É nesse contexto que o presente artigo se propõe a abordar o conceito de diversidade cultural, no capitalismo contemporâneo, com a identificação das demandas apresentadas para o campo da educação.

Uma primeira questão que se coloca é, justamente: por que o tema da diversidade cultural tem sido central no debate político internacional? Como assinalado, parece que este tema interessa ao movimento do capitalismo contemporâneo, como busca de diferenciais mercadológicos. Nesse caso, torna-se relevante investigar a abordagem do conceito de diversidade cultural no campo da economia política e da axiologia.

Como essa suposta centralidade da diversidade cultural se reflete no âmbito das políticas brasileiras? Em várias áreas, o Brasil tem demonstrado tendência a aderir às recomendações internacionais, no jogo da diplomacia. É bem provável que esteja fazendo o mesmo movimento em relação ao tema da diversidade, não necessariamente articulando ações consistentes. Essa hipótese exige verificar como os organismos internacionais e o Estado brasileiro estão dialogando em torno do tema.

Que demandas as novas políticas apresentam ao campo da educação? Se nossa linha de raciocínio estiver correta quanto às indagações anteriores, pode-se supor que haja a expectativa de que o sistema educacional deva preparar os consumidores-cidadãos para novos tipos de mercadoria, fomentando a indústria cultural. Esta hipótese torna necessário identificar que tipo de demanda é feita ao campo educacional, no que diz respeito aos documentos que divulgam as políticas públicas em torno do tema da diversidade cultural.

Para dar conta desse pensamento, o conceito de cultura será aqui tomado na sua relação com os conceitos de valor e de diversidade, no ambiente da globalização, para compreender como diversidade cultural, indústria cultural e educação se relacionam no desenvolvimento de um cidadão, conforme os interesses da nova etapa do capital.

Segundo Silvério (2005, p. 94 e 91), "temos uma Constituição inclusiva e uma hegemonia do nacional excludente". A transição de uma sociedade em que a representação monocultural, que foi construída e fixada por elites políticas e intelectuais, vem sendo substituída por uma "representação social que cotidianamente se revela dinâmica e multicultural" é uma hipótese levantada pelo sociólogo, que aponta como um dos principais elementos para a compreensão dos desafios existentes no processo brasileiro o entendimento das diferentes formas, mediante as quais se expressa e vem sendo interpretada a diversidade.

Essa observação sugere a importância da relação entre mono e multiculturalidade no jogo da diversidade, como elemento constitutivo do que o autor chama de "processo brasileiro". Isso remete a pensar o conceito de cultura não mais no singular. 
Nessa direção, Tomazi (1997) aponta três concepções de cultura que estão sempre presentes: cultura-valor, o sentido mais antigo, a ideia de cultivar o espírito, quem tem uma cultura artística, clássica ou científica; cultura alma-coletiva, sinônimo de civilização, todos têm uma cultura que gera uma identidade cultural; culturamercadoria corresponde à cultura de massa, bens, pessoas, teorias, ideologias, tudo que está disponível no mercado. Desde sua constituição, o capitalismo foi penetrando em quase todos os países e, com o desenvolvimento do comércio, da indústria e dos meios de comunicação em massa, a cultura capitalista se mundializou.

Certo de que não existe uma civilização humana, porém civilizações diferentes, Mattelart (2005) conceitua cultura como o saber, as crenças, as artes, as leis, os costumes ou toda outra faculdade ou hábito adquirido por um membro de uma sociedade. Sabemos que todos os povos e grupos sociais produzem cultura e, consequentemente, todos os indivíduos que integram esses grupos também a possuem e, geralmente, interagem com outros grupos sociais e carregam elementos de todos eles. Daí a ideia de multiculturalismo ganhar força em vários setores da vida globalizada, ainda que em contradição com a padronização.

O modo de pensar, agir e sentir das pessoas ou grupos faz com que se identifiquem e se diferenciem no seu modo de viver, expressando isso na produção de bens materiais, ideias, valores, costumes e hábitos. Nesse sentido, é sempre temerário sugerir que esteja se efetivando uma pasteurização da cultura, ainda que haja forças atuando nessa direção. Como afirma Canclini (2006, p. 201):

Cultura é o resultado de uma seleção e de uma combinação, sempre renovada, de suas fontes. É produto de uma encenação, na qual se escolhe e se adapta o que vai ser representado, de acordo com o que os receptores podem escutar, ver e compreender. As representações culturais são sempre re-apresentações, teatro, simulacro.

Dessa forma, torna-se impossível predizer o futuro da cultura ou das culturas. Elas contêm em si algo do imponderável, presente nas combinações históricas, políticas e sociais, permeadas por múltiplos elementos.

Por outro lado, é preciso cuidar para que nossa reflexão não seja tomada pelo relativismo. Adorno (2004, p. 114), no texto Cultura e administração, observando o "quase tudo" que pode ser significado com o uso da palavra cultura, afirma que:

Quem fala de cultura fala também de administração, queira ou não. A síntese de nomes tão díspares como filosofia e religião, ciência e arte, formas de vida e costumes, finalmente o espírito objetivo de uma época debaixo de uma única palavra, cultura, denuncia de antemão o olhar administrativo que reúne, classifica, pesa, organiza tudo isso desde cima.

Entretanto, também aponta que cultura e administração estão em contraposição, pois, enquanto a cultura almejaria ser a manifestação da essência pura do ser 
humano, sem relação com contextos funcionais da sociedade, ela não existe senão como cultura administrada. A cultura se desenvolve a partir de um paradoxo: se deixada ao seu livre arbítrio, ela não existe; se administrada, torna-se nociva. Mas o que a mantém como tal, como cultura? O que a faz o que é?

Podemos pensar que o "espírito objetivo de uma época" contenha em si algo de valor. Valor é uma palavra que tem sua origem no grego axiós: o que tem sentido, direção, o que é significante, relevante. No âmbito da axiologia, "os valores são fruto das diferentes projeções do espírito humano sobre a natureza, desenvolvendo-se e manifestando-se ao longo da história" (García, apud Diskin, 2000, p. 60). Já na economia política, valor é um conceito vinculado a uma práxis na qual o fator simbólicocultural tem uma relação intimamente imbricada com a vida material. Nesse ponto, voltamos ao fato de que, em nossa sociedade, a produção da vida material tem sido pautada pelo consumo característico da nova etapa do capital globalizado.

Ao mesmo tempo em que a globalização apresenta oportunidades de crescimento e enriquecimento, vemos também a emergência do intercâmbio entre as culturas, já que a diversidade cultural pode se converter em ameaça, provocando a aculturação e, algumas vezes, é utilizada como pretexto para a discriminação. A intensificação da interculturalidade favorece intercâmbios, misturas maiores e mais diversificadas do que em outros tempos, e o estudo dos processos culturais "serve para conhecer formas de situar-se em meio à heterogeneidade", como afirma Canclini (2006, p. 26).

Braudel (1989, p. 31) declara que "as civilizações, as sociedades mais brilhantes, pressupõem, dentro dos seus próprios limites, a existência de culturas, de sociedades elementares". Ao constatar a pluralidade do patrimônio cultural brasileiro, é Bosi (1992) quem declara que a admissão da pluralidade da cultura brasileira é um passo decisivo para compreendê-la. A hipótese de uma cultura unitária, coesa, poderia sugerir a expressão de uma identidade nacional. Porém, casamentos de outras culturas que conformaram nosso cotidiano material e moral apontam o caráter plural da nossa. Se, por um lado, isso pode tornar complexa a definição da identidade nacional, por outro lado, considera-se a pluralidade como uma característica dessa identidade que desafia seus analistas em novas direções menos convencionais. Talvez, por isso, vários estudiosos já prefiram adotar o plural na constituição do próprio conceito de identidade.

Mamberti (2005), por exemplo, afirma que o direito à construção individual e coletiva das identidades através das expressões culturais é elemento fundamental da promoção de uma cultura de paz. O artigo primeiro da Declaração Universal sobre Diversidade Cultural da unEsco defende a diversidade cultural como patrimônio comum da humanidade, pois é vital, como a biodiversidade para os seres humanos. 
Mas ainda é preciso retomar o fato de que a hegemonia de uma visão de mundo é resultado de uma engrenagem de relações desiguais. Se for verdade que o consumo subordina o espírito objetivo desta época, o atual movimento do capital impele a um processo de homogeneização da cultura. Harvey (2004) chama a atenção para o fato de que, há cerca de 20 anos, a palavra "globalização" se tornou chave na organização dos nossos pensamentos, revelando consequências e contradições relativas às mudanças na sua dinâmica, todas interligadas e descrevendo um panorama complexo de relações em âmbito mundial: 1) as corporações internacionais estão cada vez mais poderosas; 2 ) tem ocorrido uma feminização do mercado de trabalho vinculado a uma dispersão geográfica e cultural que dificulta a organização dos trabalhadores, tornando claro que o controle do trabalho é questão vital para a globalização; 3) tem havido um aumento nos fluxos migratórios; 4) a urbanização tornou-se hiperurbanização, afetando a organização espacial da população mundial; 5) as operações do Estado têm sido disciplinadas pelo capital monetário e financeiro, de forma jamais vista e, contraditoriamente, têm apelado ao nacionalismo populista como forma de contra-ataque à globalização; 6) há um novo conjunto de problemas ambientais globais; finalmente, 8) há o problema da manutenção da diversidade cultural.

Como temos observado, a questão da diversidade cultural não é nova nem recente, mas está colocada num novo patamar de interpenetração, tendo em vista os volumes do fluxo de informações, os deslocamentos de milhões de turistas e a circulação de artefatos especiais, mercadorias e tecnologias pelo mundo. Para além da ideia de que a globalização impele a um processo de homogeneização da cultura, nota-se que

(...) há abundantes sinais da existência de todo gênero de contramovimentos, que variam da propaganda da diversidade cultural como mercadoria a intensas reações culturais à influência homogeneizadora dos mercados globais e estridentes afirmações da vontade de ser diferente ou especial. (Harvey, 2004, p. 97)

Assim como raros são os locais ainda não atingidos pelas influências do mercado, também raras são as culturas não tocadas por ele, ainda que este seja um campo da atividade humana cuja dinâmica é imprevisível. Mas, como afirmou Adorno, a relação entre cultura e administração é, também, inquestionável.

Se a diversidade cultural é um dos mais preciosos tesouros da humanidade, pois o que há de específico na construção da identidade humana é mantido pela cultura, a desintegração de uma cultura é uma perda. Porém, a assimilação de uma cultura pode ser considerada enriquecimento. Ainda assim, o argumento é polêmico, porque a história também está repleta de exemplos em que a assimilação resultou no fim ou na subordinação de uma cultura a outra, permitindo sugerir que há culturas mais primitivas e culturas mais avançadas, situando-as hierarquicamente e servindo aos propósitos da dominação social. 
Nesse caso, poderíamos pensar que a pedida é desenvolver o respeito à pluralidade das culturas, propiciando a consideração dessa pluralidade como oportunidade de crescimento, condição de enriquecimento cultural e verdadeiro patrimônio comum da humanidade. É evidente a constante necessidade do desenvolvimento de políticas públicas orientadas ao pluralismo cultural, sobretudo no que trata do respeito pela diferença entre todos os grupos sociais, sem a pretensão de homogeneização, sem permitir a discriminação ou a dominação de uns por outros.

Contudo, entre outros fatores, é inegável a manipulação da mídia, impingindo uma cultura moldada, assim como é evidente a manipulação de poder e superioridade de algumas culturas em relação às outras. Os Estados, aderindo a determinados padrões, parecem tender a propor políticas sociais (sobretudo educacionais), cujo objetivo seja a tomada de consciência da diversidade cultural e da necessidade de adequação da formação, que enfoque a diversidade como fator de enriquecimento e não de dificuldade ou constrangimento.

Nesse sentido, parece que um dos grandes desafios da educação é lidar com a profusão de culturas. Discriminação ou pluralismo cultural? Respeitar e conhecer os valores de outras culturas não implica necessariamente adotá-los. As políticas educacionais, particularmente as políticas explícitas de interculturalidade, propõem enfoques curriculares, interferindo nos conteúdos programáticos, na formação contínua dos docentes e na gestão institucional das escolas. Evidentemente, existe uma distância entre o discurso da interculturalidade e as práticas que a realizam, o que coloca as também contraditórias relações entre discursos e praticas educacionais em questão, uma vez que, tradicionalmente, a educação tem se voltado ao estabelecimento de um padrão cultural hegemônico.

Estudiosos contemporâneos defendem uma mudança profunda de mentalidade, como Morin (2003), que declara que a ética da compreensão planetária deve ser objeto da educação do futuro e aponta como duplo imperativo antropológico: salvar a diversidade humana e salvar a unidade humana. Para tanto, identifica sete saberes necessários ao conhecimento. O primeiro é a diferença entre o erro e a ilusão, a dificuldade de percepção ou a reconstrução individual da realidade. Há a necessidade de reflexão sobre o conhecimento adquirido, já que não há verdades universais. $\mathrm{O}$ segundo saber trata dos princípios do conhecimento pertinente, que valoriza a importância da contextualização do conhecimento, já que a realidade social é multidimensional. O ensino dividido e fragmentado, por disciplina, impede a capacidade natural de contextualizar. O terceiro saber estuda a condição humana, pois fazemos parte de uma sociedade e trazemos impressas em nós as marcas de nosso ambiente social. Ao mesmo tempo em que o ser humano é múltiplo, é também uma unidade e a compreensão disso permite entender nossa realidade, nossa diversidade e nossa singularidade. O quarto saber, na intenção de derrubar o individualismo, aponta a 
compreensão humana, a importância de compreender a si mesmo e aos outros. $\mathrm{O}$ quinto saber propõe enfrentar as incertezas, o que incita à coragem. A história da humanidade sempre foi marcada por altos e baixos, catástrofes e bonanzas. Assim, o jovem deve aprender a ser forte e corajoso para viver a aventura humana. O sexto saber é imprescindível na era da globalização - a compreensão planetária - e aponta a urgência de entendermos a ameaça nuclear, a ameaça ecológica e a degradação da vida planetária. O sétimo saber necessário é a antropo-ética, a ética do gênero humano. O entendimento de que problemas econômicos são cada vez mais agravados pelo poder tecnológico pode orientar e guiar a tomada de consciência social que leva à cidadania, para que o indivíduo possa exercer sua responsabilidade.

Nesse sentido, a estrutura educacional contemporânea, conforme alerta Morin (2003), deve enfocar não apenas o acúmulo de conhecimento, mas deve levar o aluno a desenvolver a criatividade, a imaginação e o espírito de iniciativa; deve, principalmente, fazê-lo raciocinar. Superficialmente, esse enunciado está presente também noutras propostas. Contudo, o que o diferencia, como vimos antes e vale a pena ressaltar, é que, em profundidade, chega a tratar-se de uma inversão na forma convencional de pensar.

Os desafios impostos pelo mundo contemporâneo são enfrentados pela educação, que visa a nortear uma prática pedagógica que entusiasme o aluno para a aquisição do conhecimento. Morin (op. cit.) afirma que a universalização da cidadania é a resposta para conflitos humanos e educacionais, pois o aluno-cidadão precisa aprender a se situar de modo crítico e participativo no seu contexto, o que o tornará invulnerável a manipulações ideológicas da modernidade. Novamente, vemos o risco de tomar o argumento fora de seu contexto epistemológico, ou tendemos ao discurso de mudança que se esvazia na prática, além de desqualificar a teoria.

Percebemos que a identificação de nossas raízes culturais e a valorização de nossa diversidade pressupõem conhecimento do contexto situacional e histórico em que vivemos. A perda ou diminuição de caracteres próprios das culturas e aceitação de valores mais universais, assim como o achatamento de valores éticos e morais têm sido consequências das enormes transformações político-econômicas e sociais ocorridas, sobretudo, no século xx. As nações têm assistido a novas formas de brutalização do ser humano e desvalorização da vida, da saúde, da família, do respeito ao outro, que também refletem no desrespeito ao meio ambiente. Tornou-se comum afirmar que falta ética, que faltam valores em nossa sociedade.

Nesse contexto, encontramos Mota (2002), que, interessado em medir a profundidade das raízes ideológicas da consciência nacional que sustêm os ideários de tantos homens de pensamento, alerta que a cultura brasileira se reduz a uma cultura de palavras e que os intelectuais brasileiros não pensam, apenas leem. $\mathrm{O}$ autor informa que a noção de cultura brasileira surgiu no discurso ideológico de 
segmentos altamente elitizados da população e o Estado incorporou esses ideólogos, que elaboram uma noção abrangente e harmoniosa de cultura. O autor aponta Gilberto Freire como grande ideólogo da cultura brasileira, cuja obra denunciou o atraso intelectual, teórico e metodológico que caracterizava os estudos sociais e históricos no Brasil.

Além disso, Mota (op. cit.) observa que o desenvolvimento econômico, vivido pelo Brasil em meados do século $\mathrm{xx}$, gerou a necessidade de uma laicização do saber, cuja implantação possibilitou um projeto ideológico de unificação de todas as correntes educacionais. $\mathrm{O}$ autor, então, propõe que seja instalada uma implicação dialética articulada entre setores pedagógicos, culturais e industriais, visando a autoconsciência da cultura e a lucidez do destino nacional, argumentando que não somos resultantes do que fomos, mas do que pretendemos e queremos ser - o que exige consciência do que somos.

A Organização das Nações Unidas (onU), que, a despeito de todas as críticas contemporâneas, surgiu com o objetivo de preservar a paz e promover a cooperação internacional, indica que seu princípio maior é o respeito a todas as culturas. Aprofundar a compreensão e o respeito mútuos entre os povos da Terra, por meio de realizações culturais, é o objetivo da unEsco.

Em 2002, a unesco promulgou a Declaração Universal sobre a Diversidade Cultural. Embora seja um organismo reconhecido por sua atuação em benefício do avanço das condições de vários países, em seu âmbito de atuação, temos de observar o fato de que não se trata de uma instituição neutra ou infensa a determinados interesses, servindo muitas vezes como aparelho da ideologia dominante. Esta ideologia a que nos referimos é a lógica do capital, no seu movimento de globalização, como temos discutido ao longo deste artigo. Sendo o capital algo de natureza contraditória, obriga-nos a refletir criticamente sobre os elementos que compõem a sua lógica, como forma de encontrar caminhos de superação das contradições identificadas (o que estamos buscando fazer ao longo desse artigo, considerando seu recorte temático).

Na introdução do referido documento, entre outras considerações e afirmações, a unEsCo assume a globalização como desafio à diversidade, mas a afirma como criadora de condições para um diálogo renovado entre culturas e civilizações. No que se refere à diversidade cultural propriamente dita, apresenta-a como patrimônio da humanidade; associa-a ao desenvolvimento econômico; enfatiza a educação de qualidade como um direito cultural e argumenta que a cultura é uma mercadoria diferenciada:

Reafirmando que a cultura deve ser considerada como o conjunto dos traços distintivos espirituais e materiais, intelectuais e afetivos que caracterizam uma sociedade ou um 
grupo social e que abrange, além das artes e das letras, os modos de vida, as maneiras de viver juntos, os sistemas de valores, as tradições e as crenças, ${ }^{1}(\ldots)$.

Constatando que a cultura se encontra no centro dos debates contemporâneos sobre a identidade, a coesão social e o desenvolvimento de uma economia fundada no saber, (...).

Considerando que o processo de globalização, facilitado pela rápida evolução das novas tecnologias da informação e da comunicação, apesar de constituir um desafio para a diversidade cultural, cria condições de um diálogo renovado entre as culturas e as civilizações, (...).

Como se pode ver, essa introdução já deixa claro o viés da lógica capitalista sobre a compreensão do conceito de cultura e o papel da administração da diversidade. Mais adiante, o documento reconhece a importância das tradições como experiência; estimula o estabelecimento de indústrias culturais viáveis e competitivas nos planos nacional e internacional, especialmente nos países em desenvolvimento e em transição, como reforço à cooperação e à solidariedade; e recomenda que as políticas públicas nos países criem marcos reguladores.

Entre as "linhas para o plano de ação dos governos", naquilo que se refere à educação, a unEsco sugere:

1. Aprofundar a compreensão do vínculo entre diversidade cultural e desenvolvimento (...).

7. Promover, por meio da educação, uma tomada de consciência do valor positivo da diversidade cultural e aperfeiçoar, com esse fim, tanto a formulação dos programas escolares como a formação dos docentes.

8. Incorporar métodos pedagógicos tradicionais e as mídias para otimizar o processo educativo.

Como se pode observar, o documento oferece diretrizes muito objetivas que vinculam a diversidade cultural à questão econômica, além de não recuar diante de uma proposição, no mínimo polêmica nos meios educacionais, de incorporar métodos pedagógicos tradicionais e mídias para otimizar o processo educativo.

O documento também não deixa brechas ao "livre arbítrio" da cultura, enquanto recomenda aos governos a sua regulação. Em resposta a isso, o governo brasileiro criou, em agosto de 2004, a Secretaria da Identidade e da Diversidade Cultural, incumbida de promover e apoiar as atividades de incentivo à diversidade cultural como meio de promoção da cidadania. Por meio do Decreto n. 5.711/2006, artigo 11으, ficou estabelecido que compete à Secretaria da Identidade e da Diversidade Cultural:

I - promover e apoiar as atividades de incentivo à diversidade e ao intercâmbio cultural como meios de promoção da cidadania, a cargo do Ministério; 
II - instituir programas de fomento às atividades de incentivo à diversidade e ao intercâmbio cultural como meios de promoção da cidadania, a cargo do Ministério;

III - planejar, coordenar e executar as atividades relativas à recepção, análise, controle, aprovação, acompanhamento e avaliação de projetos culturais de incentivo à diversidade e ao intercâmbio cultural como meios de promoção da cidadania encaminhados ao Ministério; e

IV - subsidiar a Secretaria de Políticas Culturais no processo de formulação das políticas da área cultural relacionadas com a promoção da diversidade e do fortalecimento de identidades.

Assim, verificamos que, ao menos no plano das intenções que a legislação encerra, o Brasil adere às recomendações internacionais, garantindo-as no âmbito do jogo da diplomacia, visto que, nas linhas gerais do discurso, não há porque discordar da importância da diversidade cultural e da relevância de trabalhar em favor dela, frente aos argumentos que se constroem para o concerto das nações em torno da economia de mercado.

Voltando à Declaração Universal sobre a Diversidade Cultural, o referido documento traz, ainda, "orientações estratégicas" aos países:

a) ampliar o nível e a qualidade da escolarização da população, promovendo o acesso universal à educação e ao patrimônio cultural do país;

b) reduzir a vulnerabilidade das crianças e de adolescentes em relação a todas as formas de violência, aprimorando os mecanismos de efetivação dos seus direitos sociais e culturais;

c) promover a redução das desigualdades raciais, com ênfase na valorização cultural das etnias;

d) promover a redução das desigualdades de gênero, com ênfase na valorização das diferentes identidades;

e) ampliar o acesso à informação e ao conhecimento por meio das novas tecnologias, promovendo a inclusão digital e garantindo a formação crítica dos usuários;

f) ampliar, desconcentrar regionalmente e fortalecer as bases culturais, científicas e tecnológicas de sustentação do desenvolvimento, democratizando o seu acesso;

g) reduzir as desigualdades regionais e intra-regionais com integração das múltiplas escalas espaciais (nacional, macro-regional, sub-regional e local), valorizando as identidades e diversidades culturais e estimulando a participação da sociedade no desenvolvimento local;

h) valorizar a identidade e preservar a integridade e soberania nacionais;

i) promover os valores e os interesses nacionais e intensificar o compromisso do país com uma cultura da paz, solidariedade e de direitos humanos no cenário internacional.

Como se pode observar, o escopo de atuação "estratégica" que se propõe é tão amplo que poderia ficar sob a responsabilidade de qualquer uma das principais políticas de qualquer governo e seria obrigação de todas elas garantirem isso aos 
seus povos. Essa repetição ou a duplicidade de funções não torna de alguns a responsabilidade de muitos?

No fundo, pode-se pensar que novos órgãos são criados para ampliar o peso do Estado - no que se refere à definição dos rumos da vida social e cultural e não para solucionar problemas específicos em determinado âmbito - e um discurso como o da Declaração em pauta pode tender a cair no vazio. Entretanto, não nos apressemos, pois as coisas não são assim tão simples.

O documento também permite notar aquela forma "de cima para baixo", a que Adorno (2004) se referia no texto citado anteriormente, que desconsidera os próprios produtores da cultura. Sua atividade não deve ser espontânea, mas regulada pelos interesses do país e fomentando uma "solidariedade internacional".

É o que vemos acontecer quando, por exemplo, algumas festas populares tornam-se espetáculos e devem adequar-se a um determinado formato definido pelos seus administradores (geralmente os administradores das mídias). Determinados padrões devem ser assimilados para que a televisão transmita, algumas celebridades são convidadas para abrilhantar a festa e atrair novos espectadores, toda uma estrutura de exploração mercadológica é montada muito rapidamente, dentro dos parâmetros sempre atualizados da indústria cultural. Vimos isso acontecer com o carnaval de vários pontos do Brasil, cuja diversidade de manifestações também tem sido largamente explorada. Ainda que os maiores interesses comerciais ou os maiores investidores ainda se concentrem no eixo São Paulo-Rio, a rede que esquematiza todos os processos estende cada vez mais o seu alcance. Como exemplo desse movimento, podemos assinalar a construção de "sambódromos" em todas as capitais e em algumas grandes (e até pequenas) cidades do país.

$\mathrm{Na}$ esteira das recomendações da UNESCO, como vimos, há um estímulo ao desenvolvimento de "indústrias culturais viáveis e competitivas" - algo que chama a atenção pelo fato de um conceito que foi cunhado em perspectiva crítica seja agora utilizado, destituído do principal elemento que o definiria, como que totalmente incorporado à lógica de mercado.

Cautelosos, observamos que a indústria cultural (livro, imprensa, disco, rádio, televisão, cinema, novos produtos e suportes audiovisuais, fotografia, reprodução de obra de arte, publicidade) transforma o ato cultural em mercadoria e, assim, dissolve os traços de autenticidade, conforme Horkheimer e Adorno (1997), já que a cultura tradicional é forçada a moldar-se aos padrões mínimos de exposição à mídia. Percebemos, assim, a dificuldade de reconciliar os saberes e valorizar a diversidade, como propõem os discursos dos organismos multilaterais.

Horkheimer e Adorno (1997) cunharam o termo "indústria cultural", que acabou substituindo a expressão cultura de massa, até pela ampliação do significado 
e dos elementos que a compõem, considerando que a racionalidade técnica teria se tornado a racionalidade da própria dominação, como caráter compulsivo da sociedade alienada de si mesma. Para os autores, a indústria cultural se caracterizaria por harmonização, esquematismo, desempenho, preocupação com o detalhe técnico, repetição, distração e alienação das massas:

(...) a diferenciação técnica e social e a extrema especialização... conferem a tudo um ar de semelhança (...). Até mesmo as manifestações estéticas de tendências políticas opostas entoam o mesmo louvor do ritmo de aço (...). Os edifícios monumentais e luminosos que se levantam por toda parte são os sinais exteriores do engenhoso planejamento das corporações internacionais (...). (p. 112)

\section{$\mathrm{Ou}$, em outro ponto:}

(...) os projetos de urbanização que, em pequenos apartamentos higiênicos, se destinam a perpetuar o indivíduo como se ele fosse independente submetem-no ainda mais profundamente a seu adversário, o poder absoluto do capital (...). A unidade evidente do macrocosmo e do microcosmo demonstra para os homens o modelo de sua cultura: a falsa identidade do universal e do particular. (p. 113)

Com isso, vemos o quanto a diversidade cultural pode ser vista e entendida de forma sempre ampliada, porque envolve toda a produção da vida e da convivência humana. Assim, também não pode haver limites para o que deva ser administrado no âmbito da vida. A vida deve ser administrada. É do modo de viver das pessoas em cada localidade que se está falando. É de conhecer, mapear, organizar, selecionar, criticar, julgar, avaliar, comparar, padronizar e pasteurizar que se está falando.

Como deformar o sentido de um conceito de maneira tão "tranquila"? Como utilizá-lo significando exatamente o contrário do sentido em que fora cunhado? Numa situação como essa, é forçoso indagar que mecanismo é esse que promove a inversão dos significados sem nenhum pudor. Talvez, parte da compreensão disso esteja no próprio universo da cultura. Como afirmam Horkheimer e Adorno (1997, p. 117):

Falar em cultura foi sempre o contrário à cultura. O denominador comum "cultura" já contém virtualmente o levantamento estatístico, a catalogação, a classificação que introduz a cultura no domínio da administração (...). Quem resiste só pode sobreviver integrando-se. Uma vez registrado em sua diferença pela indústria cultural, ele passa a pertencer a ela, assim como o participante da reforma agrária ao capitalismo.

Ou, em outro ponto: "A vida no capitalismo tardio é um contínuo rito de iniciação. Todos têm que demonstrar que se identificam integralmente com o poder de quem não cessam de receber pancadas" (Horkheimer \& Adorno, op. cit., p. 114).

Por outro lado, enquanto a crítica à realidade e a retomada conceitual são necessárias, é fato que a vida pulsa no cotidiano e há ações e reações fluindo em várias 
direções, tecendo as culturas e as identidades. Nesse sentido, também há pensadores buscando instaurar o novo, as novas mentalidades ou caminhos de integração do existente, como temos visto e citamos os esforços de Edgar Morin.

Segundo Canclini (2006), por exemplo, é fundamental importar-se não apenas com o que se extingue, mas com as transformações culturais. Nesse sentido, o pesquisador argentino argumenta que hibridação não é sinônimo de fusão sem contradições, mas pode ajudar a dar conta de formas particulares de conflito geradas na interculturalidade. Ele observa que a modernização redimensiona a arte e o folclore; a modernidade é a etapa histórica, a modernização é um processo socioeconômico que vai construindo a modernidade e os modernismos, ou seja, os projetos culturais que renovam as práticas simbólicas com um sentido experimental ou crítico. Assim, já que a riqueza consiste em que a mundialização cultural não seja homogeneizado$\mathrm{ra}$, as culturas podem aprender umas com as outras.

O processo de transculturação chamado "hibridação" significa um intercâmbio de valores culturais, não necessariamente negativo, que faz possível a multiculturalidade, a valorização do pluralismo cultural, como um processo de intersecção. Entendamos multiculturalidade como um estado de coisas, um conjunto de pessoas que habitam em um mesmo território e tem diferentes origens étnicas, religiosas, raciais, nacionais. O conceito de hibridação tem em vista identidades heterogêneas, que aceitam e respeitam o diferente. Barbosa (2008) define:

\begin{abstract}
A multiculturalidade é o denominador comum dos movimentos atuais em direção à democratização da educação em todo o mundo. Os códigos elaborados pelos europeus e pelos norte-americanos brancos não são os únicos válidos, apesar de serem os mais valorizados na escola, por razões fundadas na dependência econômica, que se intensifica com a dependência cultural. A preocupação com o pluralismo cultural, a multiculturalidade, $o$ interculturalismo nos leva necessariamente a considerar e respeitar as diferenças, evitando uma pasteurização homogeneizante na escola.
\end{abstract}

Quando duas culturas distintas ou parecidas são mutuamente absorvidas, formando uma nova e diferente cultura, chamamos de aculturação, que é um processo de desconstrução da identidade, um processo de molde social imposto por uma sociedade distinta. Caso se promova um fecundo diálogo intercultural, as culturas podem enriquecer-se umas com as outras, já que todas são boas. A mais exigente gestão da diversidade cultural é o multiculturalismo, que só se desenvolve se houver transformação mútua, negociação e convicção. Nenhum modelo é perfeito e definitivo, como afirma Marquez (2005):

O multiculturalismo pode e deve evoluir. Uma direcção possível - o interculturalismo - acentua o seu carácter interactivo e relacional. Mais do que uma co-existência pacífica de diferentes comunidades, o modelo intercultural afirma-se no cruzamento e miscigenação 
cultural, sem aniquilamentos, nem imposições. Muito mais do que a simples aceitação do "outro", a verdadeira tolerância numa sociedade intercultural propõe o acolhimento do outro e transformação de ambos com esse encontro.

Como alerta Barbosa (2008), o que precisamos é manter uma atmosfera investigadora na sala de aula acerca das culturas compartilhadas pelos alunos, tendo em vista que cada um de nós participa no exercício da vida cotidiana de mais de um grupo cultural. Assim, também para Pais (2007, p. 153):

\begin{abstract}
Constitui a educação o único processo pelo qual é possível preservar, restaurar ou restabelecer uma civilização, na medida em que pode realizar a reinserção das pessoas no processo histórico de uma cultura. Para tanto, é necessário que a comunidade humana em questão se organize e se sustente permanentemente, segundo os princípios básicos do humanismo, da racionalidade e da civilização: liberdade, igualdade, fraternidade.
\end{abstract}

A indústria cultural engessa, impinge, subordina; a educação pode conduzir à consciência que pondera, flexibiliza e liberta, valendo-se da proposição de projetos político-pedagógicos interdisciplinares, que visam a resgatar e tentar uma concepção intercultural de valores em nossa sociedade.

A educação é desafiada a encontrar estratégias didáticas voltadas para o interculturalismo, a promover o entendimento da lógica do capitalismo, a contabilizar o enriquecimento proporcionado na irreversibilidade da globalização e a cultivar o respeito ao preservar as diferenças culturais. Para que não seja apenas um jogo visando a atender as recomendações internacionais, esperam-se ações consistentes.

$\mathrm{O}$ abismo existente entre os discursos e as ações concretas talvez se deva, em parte, ao despreparo e ignorância dos agentes educacionais. No planejamento escolar anual, geralmente se privilegiam conteúdos de projetos que contemplam o estudo e a valorização da diversidade; por outro lado, existe a dificuldade na aceitação da mudança de paradigma, pois muitos ainda mantêm a visão de hegemonia cultural, já que não é de hoje que se entende a cultura brasileira a partir de padrões europeus e norte-americanos.

Alguns professores abraçam a ideia de valorização da cultura local como forma de resgate da identidade cultural, em atendimento às propostas da educação contemporânea. Porém, muitos sucumbem aos apelos midiáticos e nem percebem a possível aculturação, a forçosa homogeneização imposta. O docente ainda está despreparado, a comunidade se abstém, os jovens são absorvidos pelas novas propostas do mundo globalizado, o que gera a vergonha das próprias origens, como se apenas o que vem de fora fosse bom, tivesse "valor".

A complexidade do mundo em que vivemos torna inevitável a hibridação, que ocorre cada vez mais de forma mais acelerada e acentuada. Entretanto, a educação 
apresenta uma teoria que vem prescrita por organismos internacionais, por gabinetes de secretarias e nem sempre é adequadamente absorvida por quem a executa.

Assim, como esperar compromisso com questões sociais que afetam a comunidade? Como gerar mudanças no meio social? Como valorizar o percurso profissional dos docentes se suas ações não forem profícuas?

Se pensarmos a educação da atualidade como mercadoria, podemos indagar como tem sido o consumo de uma educação para a diversidade. As várias discussões sobre a proteção e promoção da diversidade cultural são mediadas por inúmeros organismos. Sob esse ponto de vista percebemos que, ainda que processos sugeridos por propostas internacionais gerem inicialmente exacerbado otimismo, o diálogo intercultural ainda encontra muitos obstáculos.

\section{Nota}

1. Definição de acordo com as conclusões da Conferência Mundial sobre as Políticas Culturais (mondiacult, México, 1982), da Comissão Mundial de Cultura e Desenvolvimento (Nossa Diversidade Criadora, 1995) e da Conferência Intergovernamental sobre Políticas Culturais para o Desenvolvimento (Estocolmo) - conforme consta na Declaração Universal da Diversidade Cultural de 2002.

\section{Referências}

ADORNO, T.W. Cultura y administración. In: Adorno, T.W. Escritos Sociológicos I. Madrid: Akal, 2004. (Obras completas, 8).

AGUIRRE, E. Diário de los yacimientos de la Sierra de Atapuerca. Atapuerca: Fundação Atapuerca, 2006-2007.

BARBOSA, A.M. Arte: perspectivas multiculturais; A multiculturalidade na educação estética. In: Debates: multiculturalismo e educação. Disponível em: <www.tvebrasil.com.br/salto/boletins2002/mee/meetxt3.htm>. Acesso em: 15 jan. 2008.

BORGES, E.; MEDEIROS, C.A.; D'ADESKY, J. Racismo, preconceito e intolerância. São Paulo: Atual, 2002.

BOSI, A. Plural, mas não caótico. In: Bosı, A. Cultura brasileira: temas e situações. 2. ed. São Paulo: Ática, 1992. p. 7-15.

BRASIL. Ministério da Cultura. Secretaria da Identidade Cultural. Fomento à identidade e à diversidade cultural no contexto brasileiro. Disponível em: <www.minc.gov.br> . Acesso em: 12 maio 2007.

BRAUDEL, F. Gramática das civilizações. Trad. de Telma Costa. Lisboa: Teorema, 1989. 
CANCLINI, N.G. Culturas híbridas: estratégias para entrar e sair da modernidade. São Paulo: Edusp, 2006. (Ensaios Latino-Americanos, v. 1).

DISKIN, L. Ética: um desafio à desigualdade. In: Esteves, S.A.P. (Org.). O dragão e a borboleta. São Paulo: Axis Mundi; AMcE, 2000. p. 53-62.

HARVEY, D. A globalização contemporânea: espaços de esperança. Rio de Janeiro: Loyola, 2004.

HORKHEIMER, M.; ADORNO, T.W. A indústria cultural: o esclarecimento como mistificação das massas. In: Adorno, T.W.; Horkheimer, M. Dialética do esclarecimento. São Paulo: Zahar, 1997. p. 113-156.

MAMBERTI, S. Pronunciamento do secretário na IV Conferência de Educação e Cultura na Câmara dos Deputados. Disponível em: <www.cultura.gov.br/politicas/identidade_e_ diversidade/index.html>. Acesso em: mar. 2006.

MARQUEZ, R. Pontes e abismos em defesa do interculturalismo. 2005. Disponível em: $<$ homomigratius.blogspot.com/2005/11/pontes-e-abismos-em-defesa-do.html>. Acesso em: 15 jan. 2008.

MATTELART, A. Diversidade cultural e mundialização. São Paulo: Parábola, 2005.

MORIN, E. Os sete saberes necessários à educação do futuro. 7. ed. São Paulo: Cortez, 2003.

MOTA, C.G. Ideologia da cultura brasileira. São Paulo: Ática, 2002.

PAIS, C.T. Considerações sobre a semiótica das culturas, uma ciência da interpretação: inserção cultural, transcodificações transculturais. Acta Semiótica et Linguística, São Paulo, v. 11, p. 149-158, 2006.

PEREIRA, I.L.L.; HANNAS, M.L. Pedagogia na prática: propostas para uma educação integral. São Paulo: Gente, 2001.

SILVÉRIO, V.R. A (re)configuração do nacional e a questão da diversidade. In: AbRAmowicz, A.; Silvério, V.R. (Org.). Afirmando diferenças: montando o quebra cabeça da diversidade na escola. Campinas: Papirus, 2005. p. 13-26.

TOMAZI, N.D. Sociologia da educação. São Paulo: Atual, 1997.

UNESCO. Declaração Universal sobre a Diversidade Cultural. 2002. Disponível em: <http:// unesdoc.unesco.org/images/0012/001271/127160por.pdf>. Acesso em: 15 mar. 2008.

Recebido em abril de 2008.

Aprovado em fevereiro de 2009. 